\title{
Correction to: Genetic and genomic basis of the mismatch repair system involved in Lynch syndrome
}

\author{
Kazuo Tamura ${ }^{1}$ (1) Motohide Kaneda ${ }^{1} \cdot$ Mashu Futagawa $^{1} \cdot$ Miho Takeshita $^{1} \cdot$ Sanghyuk Kim $^{1} \cdot$ Mina Nakama $^{2}$. \\ Norihito Kawashita ${ }^{1}$ Junko Tatsumi-Miyajima ${ }^{1}$
}

Published online: 31 July 2019

(c) Japan Society of Clinical Oncology 2019

\section{Correction to: International Journal of Clinical Oncology https://doi.org/10.1007/s10147-019-01494-y}

In the original publication, part d of Fig. 2 was mistakenly not included. The corrected Fig. 2 is given in this Correction.

Also "MLH1, MSH2, MSH6, PMS2" in legend of Fig. 2 are not to be italicized.

The section, "Effectiveness of immune check point blockades and a hypermutable state (high tumor mutation burden)" should read as:

Effectiveness of immune check point blockades and a hypermutable state (high tumor mutational burden).

The original article was corrected.

The original article can be found online at https://doi.org/10.1007/ s10147-019-01494-y.

Kazuo Tamura

tamura@life.kindai.ac.jp

1 Division of Medical Genetics, Master of Science, Graduate School of Science and Engineering Research, Kindai University, Higashiosaka, Japan

2 Division of Clinical Genetics, Gifu University Hospital, Gifu, Japan
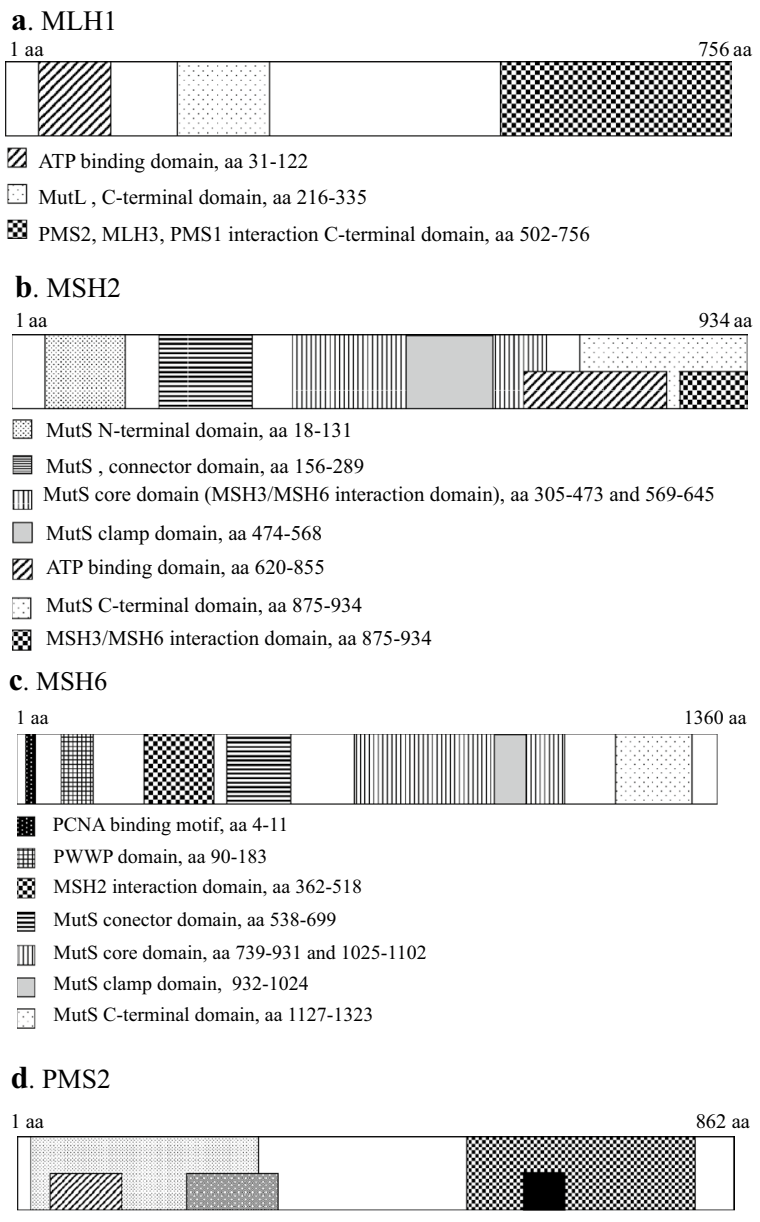

ATP binding domain, aa 35-159

MutL, C-terminal domain, aa 227-364

MutL , N-terminal domain, aa 13-343

Q MLH1 interaction C-terminal domain, aa 678-822

Endonuclease active site, aa 698-715

Fig. 2 Structure of mismatch repair proteins: a MLH1, b MSH2, c MSH6, d PMS2

Publisher's Note Springer Nature remains neutral with regard to jurisdictional claims in published maps and institutional affiliations. 